EDITORIAL
Rev Colombiana Cienc Anim 2016; 8(1):5-6.

\title{
IMPORTANCIA DE LOS OVINOS EN LOS SISTEMAS DE PRODUCCIÓN PECUARIO: PERSPECTIVA
}

\author{
IMPORTANCE OF SHEEP IN LIVESTOCK PRODUCTION SYSTEMS: \\ PERSPETIVE
}

\author{
MONTES V. DONICER, Ph.D, PEREZ C. ALEXANDER, Ph.D, DE LA OSSA V. JAIME, Ph.D.
}

Editor Revista Colombiana de Ciencias Animal - RECIA Universidad de Sucre, Facultad de Ciencias Agropecuarias, Colombia. Correspondencia: jaimedelaossa@yahoo.com

\begin{abstract}
El más grande reto que la humanidad debe enfrentar en las próximas décadas es el uso racional de los recursos naturales, y al mismo tiempo producir un volumen suficiente de alimento de calidad para satisfacer las demandas de una población humana creciente. La necesidad de producir alimentos de calidad e inocuos, demanda del sector agropecuario implementar de acciones para incrementar la producción agrícola y pecuaria (SALAZAR, 2015). La producción pecuaria tiene un gran impacto en recursos naturales como el agua, la tierra y la biodiversidad, contribuyendo significativamente en el cambio climático, de forma directa o indirectamente, a través del pastoreo o de la producción de cultivos forrajeros. La producción pecuaria ocupa aproximadamente el 30 por ciento de la superficie terrestre libre de hielo y en muchas situaciones se constituye en la principal fuente de contaminación terrestre (STEINFELD et al., 2009). En el presente, el sector pecuario atraviesa una compleja transformación, puesto que ha transformando los patrones de distribución geográfica de la producción pecuaria. Asimismo, se registra cambio en las especies utilizadas, con un crecimiento acelerado de la producción de especies monogástricas y una desaceleración de la producción de rumiantes.
\end{abstract}

Para mitigar el impacto ambiental de los sistemas comerciales de producción animal de especies menores, se hace necesario desarrollar sistemas eficientes de producción que aprovechen los recursos animales y vegetales disponibles (SANDOVAL et al., 2013). Entre las especie s menores, las ovejas de pelo han ido evolucionando bajo la influencia selectiva de la naturaleza y del hombre, adaptándose muy bien a los diferentes ambientes tropicales, resultando de mucha importancia para países en vías en desarrollo. Sin embargo, la ovino-cultura, en Colombia se ha desarrolla con niveles tecnológico bajo, tradicionalmente vinculada a economías de subsistencia, concentrada en pequeños rebaños, que reflejan reducida aplicación de nuevas técnicas en cada una de las áreas de producción (ARÉVALO y CORREA, 2013). Las investigaciones sobre ovinos en los países en desarrollo han estado limitadas en las últimas décadas, debido principalmente a la escasez de recursos estatales. Adicionalmente, el sector presenta poca organización, presentando escasa vinculación con la agroindustria. Por tanto, se debe intensificar trabajos en los sistemas de producción en los cuales se combinen esquemas de investigación, producción y extensión (GONZÁLEZ et al., 2010). En la actualidad, en Colombia, son pocas las investigaciones desarrolladas sobre el sector ovino. Aunque en la literatura se encuentran reportes de algunos trabajos realizados por grupos de investigación en diferentes instituciones, presentando productos relacionados en las área de recursos genéticos, alimentación y nutrición. En el presente, estudios generalizados de la diversidad genética de ovinos de pelo, brindara información relevante para su manejo eficiente, con el fin de generar alternativas económicas que proteger la seguridad alimentaria y la competitividad del sector a nivel nacional e internacional generando ventajas competitivas. 


\section{Referencias}

ARÉVALO, A.; CORREA G. 2013. Tecnología en la ovinocultura colombiana: estado del arte. Revista Ciencia Animal. 6:125-142.

GONZÁLEZ-GARDUÑO, R.; TORRES-HERNÁNDEZ, G.; ARECE-GARCÍA, J. 2010. Comportamiento productivo y reproductivo de ovinos Pelibuey en un sistema de pariciones aceleradas con tres épocas de empadre al año. Zootecnia Tropical 28(1):51-56.

SALAZAR, C. O. 2015. Evaluación de la implementación de Buenas Prácticas Pecuarias en la producción de ovinos y caprinos en la zona metropolitana de los municipios de Bucaramanga y Lebrija. [Trabajo de grado Maestría]. Universidad de Manizales Facultad de Ciencias Contables Económicas y Administrativas; Manizales, Colombia.

SANDOVAL-CASTRO.; CARLOS, A.; SARMIENTO-FRANCO.; LUÍS; SANTOS-RICALDE.; RONALD, H. 2013 ¿Qué son y cuál es el papel de las especies menores? Bioagrociencias, 6(2):51-56

STEINFELD, H.; GERBER, P.; WASSENAAR, T.; CASTEL, V.; ROSALES, M.; HAAN, C. 2009. La larga sombra del Ganado, problemas ambientales y opciones. FAO - LEAD - FIDA. Roma, $493 \mathrm{p}$ 